\title{
Induction of liver hypertrophy for extended liver surgery and partial liver transplantation: State of the art of parenchyma augmentation-assisted liver surgery
}

\author{
Philip C. Müller ${ }^{1}$ - Michael Linecker ${ }^{2}$ - Elvan O. Kirimker ${ }^{3} \cdot$ Christian E. Oberkofler $^{1} \cdot$ Pierre-Alain Clavien $^{1}$. \\ Deniz Balci ${ }^{3} \cdot$ Henrik Petrowsky $^{1}$
}

Received: 22 February 2021 / Accepted: 3 March 2021 / Published online: 19 March 2021

(C) The Author(s) 2021

\begin{abstract}
Background Liver surgery and transplantation currently represent the only curative treatment options for primary and secondary hepatic malignancies. Despite the ability of the liver to regenerate after tissue loss, 25-30\% future liver remnant is considered the minimum requirement to prevent serious risk for post-hepatectomy liver failure.

Purpose The aim of this review is to depict the various interventions for liver parenchyma augmentation-assisting surgery enabling extended liver resections. The article summarizes one- and two-stage procedures with a focus on hypertrophy- and corresponding resection rates.

Conclusions To induce liver parenchymal augmentation prior to hepatectomy, most techniques rely on portal vein occlusion, but more recently inclusion of parenchymal splitting, hepatic vein occlusion, and partial liver transplantation has extended the technical armamentarium. Safely accomplishing major and ultimately total hepatectomy by these techniques requires integration into a meaningful oncological concept. The advent of highly effective chemotherapeutic regimen in the neo-adjuvant, interstage, and adjuvant setting has underlined an aggressive surgical approach in the given setting to convert formerly "palliative" disease into a curative and sometimes in a "chronic" disease.
\end{abstract}

Keywords Liver surgery · Liver augmentation · Portal vein embolization · Transarterial chemoembolization · Two-staged hepatectomy $\cdot$ Associating liver partition and portal vein ligation for staged hepatectomy

\section{Abbreviations \\ ALPPS Associating liver partition and portal vein ligation for staged hepatectomy \\ CRLM Colorectal liver metastasis \\ DFS Disease-free survival \\ FLR Future liver remnant \\ HCC Hepatocellular carcinoma}

Henrik Petrowsky

henrik.petrowsky@usz.ch

1 Swiss HPB and Transplantation Center, Department of Surgery and Transplantation, University Hospital Zurich, Zurich, Switzerland

2 Department of Surgery and Transplantation, University Medical Center Schleswig-Holstein, Campus Kiel, Kiel, Germany

3 Department of Surgery and Liver Transplantation Unit, Ankara University School of Medicine, Ankara, Turkey

$\begin{array}{ll}\text { HV } & \text { Hepatic vein } \\ \text { HVE } & \text { Hepatic vein embolization } \\ \text { LD } & \text { Living donor } \\ \text { PHC } & \text { Perihilar cholangiocarcinoma } \\ \text { PHLF } & \text { Post-hepatectomy liver failure } \\ \text { PHT } & \text { Portal hypertension } \\ \text { PV } & \text { Portal vein } \\ \text { PVE } & \text { Portal vein embolization } \\ \text { PVL } & \text { Portal vein ligation } \\ \text { OS } & \text { Overall survival } \\ \text { RAPID } & \text { Resection and partial liver segment } \\ & \text { 2/3 transplantation with delayed total } \\ & \text { hepatectomy } \\ \text { RASPE } & \text { Radiological simultaneous portohepatic vein } \\ & \text { embolization } \\ \text { RCT } & \text { Randomized controlled trial } \\ \text { TACE } & \text { Transarterial chemoembolization } \\ \text { TSH } & \text { Two-staged hepatectomy }\end{array}$




\section{Introduction}

Liver surgery and transplantation currently represent the only curative treatment options for primary and secondary hepatic malignancies [1]. Despite the unique ability of the liver to regenerate after major tissue loss, 25-30\% future liver remnant (FLR) is considered the minimum requirement for patients without underlying liver disease [2]. However, major hepatectomies are associated with a serious risk for posthepatectomy liver failure (PHLF) especially in the scenario of underlying liver disease. Patients with extensive colorectal liver metastases (CRLM) or large hepatocellular carcinoma (HCC) often present with locally unresectable hepatic disease at the time of diagnosis due to a too small FLR, which is often the barrier for a curative approach.

A variety of developments have been introduced over the last decades to augment the volume of the FLR facilitating most extended liver resections. Exactly 100 years ago, Rous and Larimore first reported on the effect of portal vein occlusion in a rabbit model [3]. After left portal vein ligation (PVL), they observed hypertrophy of the contralateral and atrophy of the ipsilateral liver within 3 months. At that time, the intentional use of PVL to induce liver growth has not been considered, as major blood loss was still the main obstacle limiting hepatic surgery, which was still responsible for the majority of procedure-related mortalities. It took until 1975, when Honjo et al. reported the first clinical case of PVL for unresectable liver cancer.[4] In 1984, Makuuchi et al. introduced the principle of portal vein occlusion-induced liver augmentation into clinical practice [5]. Instead of PVL, he applied preoperative transcatheter embolization of portal branches in analogy to tumor-induced occlusion of the portal vein. In the inaugural series, portal vein embolization (PVE) was performed in 14 patients with hilar cholangiocarcinoma, in whom an extended hepatectomy was successfully performed 6 to 41 days after PVE [6]. Further steps included the introduction of intentionally planned two-staged hepatectomies (TSH) utilizing PVL and PVE for liver parenchyma augmentation to treat previously unresectable multiple metastases. The main drawback of PVE/PVL is a relatively long waiting period between liver growth induction and liver resection including the pending hazard of tumor progression. In addition, a failure to grow is not infrequently observed rendering resection rates well below $50 \%$. To overcome these limitations, new treatment concepts such as associating liver partition with portal vein ligation for staged hepatectomy (ALPPS), combined PVE/ hepatic vein embolization (HVE), and resection and partial liver segment $2 / 3$ Transplantation with delayed total hepatectomy (RAPID) were recently introduced. The aim of this review is to present the different strategies of parenchyma augmentation-assisted liver surgery with its main indications, rationale, and limitations.
Definition of parenchyma augmentation-assisted liver surgery

We define parenchyma augmentation-assisted liver surgery as any hepatobiliary surgery or liver transplantation procedure, which integrates means of liver parenchyma augmentation for a too small FLR or partial graft in order to prevent PHLF or small-for-size syndrome, and thus perform safe surgery. Interventions for tissue augmentation can be either applied before surgery in one-stage procedures such as preoperative PVE or are an intraoperative element at stage-one surgery of two-stage procedures including conventional TSH, ALPPS, or RAPID procedures.

\section{One-stage hepatectomy with portal vein embolization (+ segment IV embolization)}

Makuuchi et al. introduced PVE in the setting of perihilar cholangiocarcinoma (PHC) based on the principle that occlusion of a portal branch leads to an ipsilateral atrophy and a subsequent hypertrophy of the contralateral lobe (Fig. 1) [5, 6]. The concept was developed to increase the resection rate and minimizing the risk of PHLF after extended resections in PHC [7-9].

A large meta-analysis from 2008 including 1088 patients showed an FLR augmentation after transileocolic PVE of 9.7\% versus $12 \%$ after percutaneous transhepatic PVE. PostPVE morbidity was low $(2.2 \%)$ without any postinterventional mortality. Completion hepatectomy could be achieved in $85 \%$ of the patients 29 days after PVE. Main reasons for non-resection following PVE were progression of liver metastasis $(n=43)$, extrahepatic spread $(n=35)$, and inadequate hypertrophy of remnant liver $(n=18)$. In the postoperative course, $2.5 \%$ of patients had transient liver failure and $0.8 \%$ experienced acute liver failure leading to death [10]. In 2018, Wajswol et al. performed a meta-analysis of 18 articles with 607 patients undergoing PVE for major hepatic resections [11]. The technical success rate was $99 \%$ and the percutaneous transhepatic PVE was the most common approach (contralateral $n=417$, ipsilateral 132). Major complications after PVE occurred in 19 patients (3.1\%). The time interval between PVE and volume assessment was highly variable and ranged from 2 to 10 weeks. The authors found a relative hypertrophy rate of $49 \%$. Liver resection was finally performed in 461 of 607 patients (76\%). Similarly to the previous meta-analysis, main reasons for non-resection were disease progression $(n=114)$ and insufficient FLR hypertrophy $(n=24)$. Postoperative liver insufficiency occurred in 21 patients $(4.5 \%)$ [11].

Aiming for a right trisectionectomy, segment IV portal branches from the left portal system may be embolized in addition to the embolization of the right portal trunk. This 
a
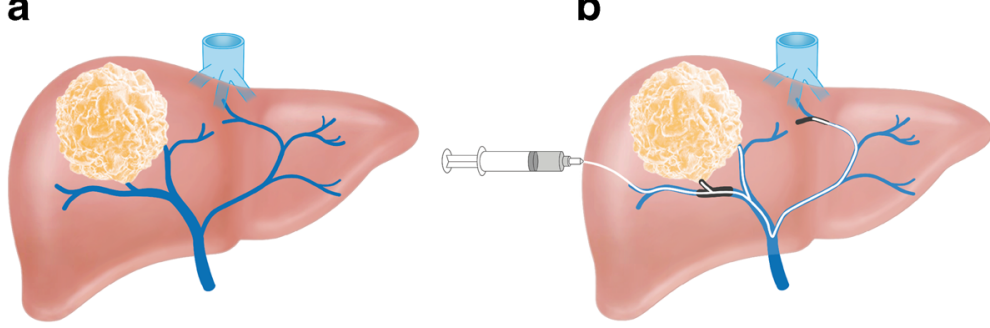

C

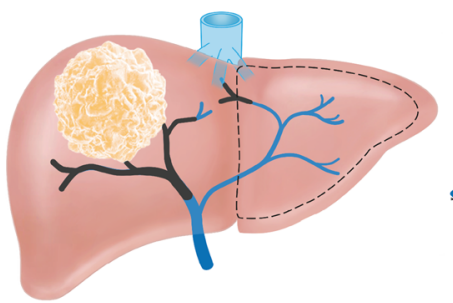

d

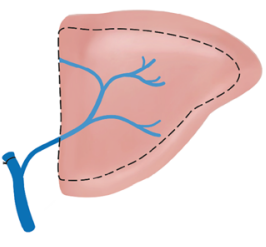

Fig. 1 Patient with a large single tumor potentially resectable by single stage hepatectomy but with a small FLR (A). Portal vein embolization of the tumor-bearing side can be used for tissue augmentation (B). After sufficient hypertrophy (C), typically $4-8$ weeks after embolization, completion hepatectomy is performed (D)

experience increased regeneration. Although the exact pathophysiologic mechanism behind regeneration after PVE/HVE is not fully understood, HVE theoretically decreases the hepatic buffer response of increased hepatic arterial inflow following PVE [17, 20, 21]. Furthermore, the development of portovenous collaterals to the deportalized liver seems to occur early after PVE, but not in PVE/HVE. In a porcine model, portal vein perfusion stayed limited to the non-embolized segments after PVE/HVE, while 7 days after PVL alone the entire liver was reperfused with portal blood. This suppression of portovenous collaterals in PVE/HVE is a potential explanation of accelerated volume augmentation [21].

Sequential HVE after insufficient liver regeneration after PVE was first described in 2009 by Hwang et al. in 12 patients. In 9 patients undergoing hepatectomy, the FLR before PVE was 35\%, 2 weeks after PVE 40\%, and 2 weeks after HVE 44\% [22]. Compared to PVE alone, this sequential approach did not reduce the time to resection and therefore as well not the drop-out of patients from potentially curative resection. In order to eliminate the waiting time between PVE and HVE, Guiu et al. introduced the concept of simultaneous PVE and HVE in 2016. In their initial report, seven patients successfully underwent PVE/HVE. After a mean time of 23 days (13-30 days), the FLR increased from 28 to $41 \%$ and resection was achieved in 6/7 patients [17].

To achieve combined PVE/HVE, the right hepatic vein (HV) is accessed under ultrasound guidance, then the right PV is accessed using the same technique. PVE is performed with iodized oil (e.g., lipiodol) and n-butyl-cyanoacrylate, without segment IV embolization. Then an Amplatzer a
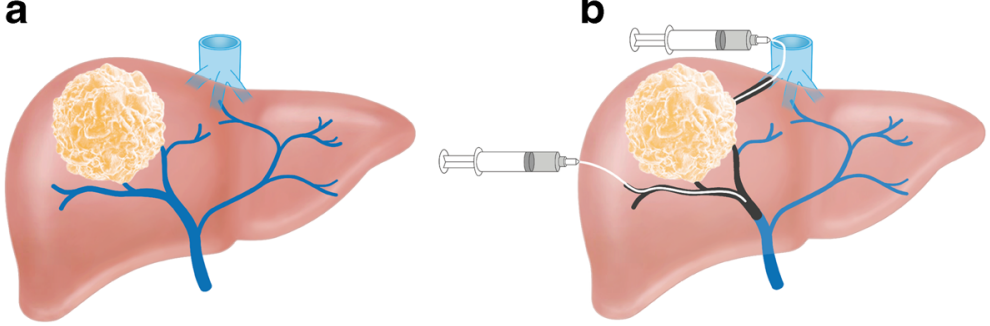

C

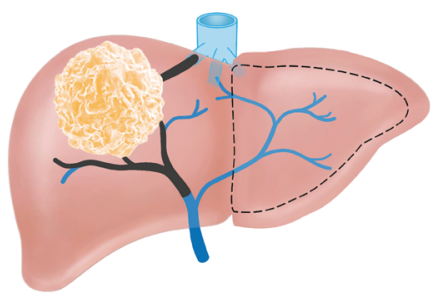

d

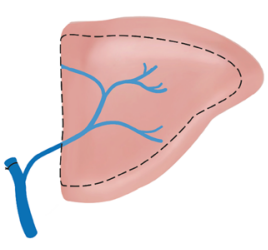

Fig. 2 Patient with a large single tumor (A) that is amenable to a single stage hepatectomy, but has an insufficient FLR requires tissue augmentation by combined portal vein- and hepatic vein embolization of the tumor-bearing side (B). After sufficient hypertrophy (C), typically 4-8 weeks after embolization, completion hepatectomy is performed (D) 
Vascular II Plug is deployed in the right HV. In the original description, the authors furthermore checked for distal branches of the right $\mathrm{HV}$ and potential veno-venous collaterals. Embolization of these branches was then performed using a lipiodol-n-butyl-cyanoacrylate mixture [17, 23].

Since the first publication, seven further reports including between 6 and 37 patients have been published [17, 18, 23-28]. PVE/HVE was mainly used to treat CRLM (55\%); however, most studies included both primary and secondary liver tumors [29]. No serious adverse events and especially no extensive liver necrosis has been reported after PVE/HVE thus far. Therefore, arterial perfusion seems to be sufficient in the embolized hemi-liver. The interval between embolization and hepatic resection ranged from 21 to 45 days. Compared to PVE alone, an accelerated liver growth is postulated after PVE/HVE. However, a comparison of clinical data is sometimes difficult due to the use of different metrics to quantify hypertrophy. Compared to the baseline FLR volume, a hypertrophy of 35-60\% was observed after PVE/HVE $[18,23,27,28]$. The hypertrophy of the liver resulted in resection rates between 67 and $100 \%$ [26, 28], while the latest review reported an overall resection rate of $87 \%$ [29]. Disease progression was the reason for drop out in 16/17 patients. Despite the limited evidence at the moment, there are currently two prospective trials recruiting. The HYPER-LIV01 trial (NCT03841305) is a randomized single-center trial from France [30], while the DRAGON trial (NCT04272931) is an international prospective multicenter trial.

\section{One-stage hepatectomy with sequential transarterial chemoembolization and portal vein embolization in HCC}

Major hepatic resection in HCC patients is often more challenging than for other hepatic malignancies due to the underlying liver disease or cirrhosis, which are associated with a higher risk of hepatic failure.[31] Compared to PVE in healthy livers, the degree of PVE-triggered hypertrophy in chronic liver disease is less predictable and PVE might theoretically induce a compensatory increase in hepatic arterial flow in the embolized segments [32]. Therefore, sequential transarterial chemoembolization (TACE) and PVE was proposed to control HCC, thereby buying time to augment liver volume (Fig. 3). For TACE, selective catheterization of the right hepatic artery is performed, then chemotherapy and an emulsion of iodized oil (e.g., lipiodol) is infused into the selected feeding artery. Afterwards, embolization with microspheres (e.g., absorbable gelatin sponge particles) is performed until arterial stasis is achieved (Fig. 4). TACE has antitumor effects by occluding tumor feeding vessels and showed promising results in HCC patients with chronic liver disease with a tumor response in half of the patients [33-36]. Evaluating the volumetric changes, different studies showed that sequential TACE and PVE induced even a greater hypertrophy in the non-embolized liver than PVE alone (Table 1) [34, 38, 39]. The time interval from TACE to PVE was 30 days (range 9120 days) and from PVE to surgery 28 days (range 21-45 days) in a systematic review [40]. In retrospective studies, TACE + PVE led to a greater hypertrophy $[34,35,38,39]$ with improved overall survival (OS) $[35,39]$ and disease-free survival (DFS) $[34,35,38,39]$ as compared to PVE alone. However, the advantages of TACE need to be carefully balanced against its adverse events. Detoriating liver function, ischemic cholangitis, and intrahepatic abscess have been repeatedly reported $[33,37,41]$. On the other hand, failure to achieve sufficient hypertrophy after TACE and PVE indicates an impaired capacity of the liver to regenerate in patients with chronic liver disease. This feature can be used as "dynamic" liver function test to identify patients who are eligible for surgery.

\section{Conventional two-stage hepatectomy with portal vein ligation or portal vein embolization}

In 2000, Adam et al. introduced the concept of TSH to treat previously unresectable multiple CRLM due to insufficient FLR. In a first stage, the highest possible number of metastases were removed, while the intention of this first operation was not clearance of all metastases. After sufficient hypertrophy with an interval of 2-14 months, 13 of 16 patients (81\%) underwent successful hepatectomy to remove the remaining tumors [42]. Since the aforementioned concept still had a considerable risk of PHLF, Jaeck et al. combined TSH with PVE. In a first step, clearing of the hemi-liver with less tumor load (most often the left side) was performed by resection and/or ablation, followed by PVE immediately after stage 1 surgery and second-stage hepatectomy after sufficient augmentation of the FLR, usually after 5-8 weeks (Fig. 5). This concept was successfully applied in 25 of 33 patients (76\%) with CRLM without perioperative mortality and a 1- and 3-year survival rate of $70 \%$ and $54 \%$ [43].

To minimize the number of procedures and the associated risks, the Belghiti group suggested simultaneous portal vein ligation (PVL) during the clearing of the left hemi-liver as a surgical variant of portal vein occlusion [44-46]. A recent meta-analysis including 21 studies compared 1953 PVE and 123 PVL patients. The authors found no difference in terms of FLR hypertrophy (PVE $43 \%$ vs. PVL 39\%), although there was a high variability in time interval between PVE/PVL and hypertrophy evaluation. Post-interventional morbidity after PVE (3.9\%) and PVL (5.2\%) was comparable. However, the number of uncompleted two-stage resections due to 
Fig. 3 Clinical case of transarterial chemoembolization and sequential portal vein embolization (University of Zurich). This 69-year-old patient presented with a $7-\mathrm{cm}$ hepatocellular carcinoma (HCC) in liver segments V/VIII and an alphafetoprotein (AFP) of $42.649 \mu \mathrm{g} / \mathrm{l}$ (A/B). No portal hypertension or liver cirrhosis was present. For a right hemihepatectomy, a sFLR of $27 \%$ was calculated. Since the indocyanine green (ICG) test showed impaired liver function with a plasma disappearance rate (PDR) of $12.1 \% / \mathrm{min}$ (normal value $>18 \% / \mathrm{min}$ ) and ICG retention rate $\left(\mathrm{R}_{15}\right)$ of $14.7 \%$ (normal value $<10 \%$ ), we opted for transarterial chemoembolization (C/D)followed by portal vein embolization 2 weeks later $(\mathbf{E} / \mathbf{F})$. After the successful embolization, the AFP dropped to $209 \mu \mathrm{g} / \mathrm{l}$ and the sFLR increased to $39 \%$ (G/ H). We then performed a right hemihepatectomy $(\mathbf{I} / \mathbf{J})$. Three months postoperatively, the patient is tumor-free and in a good general condition

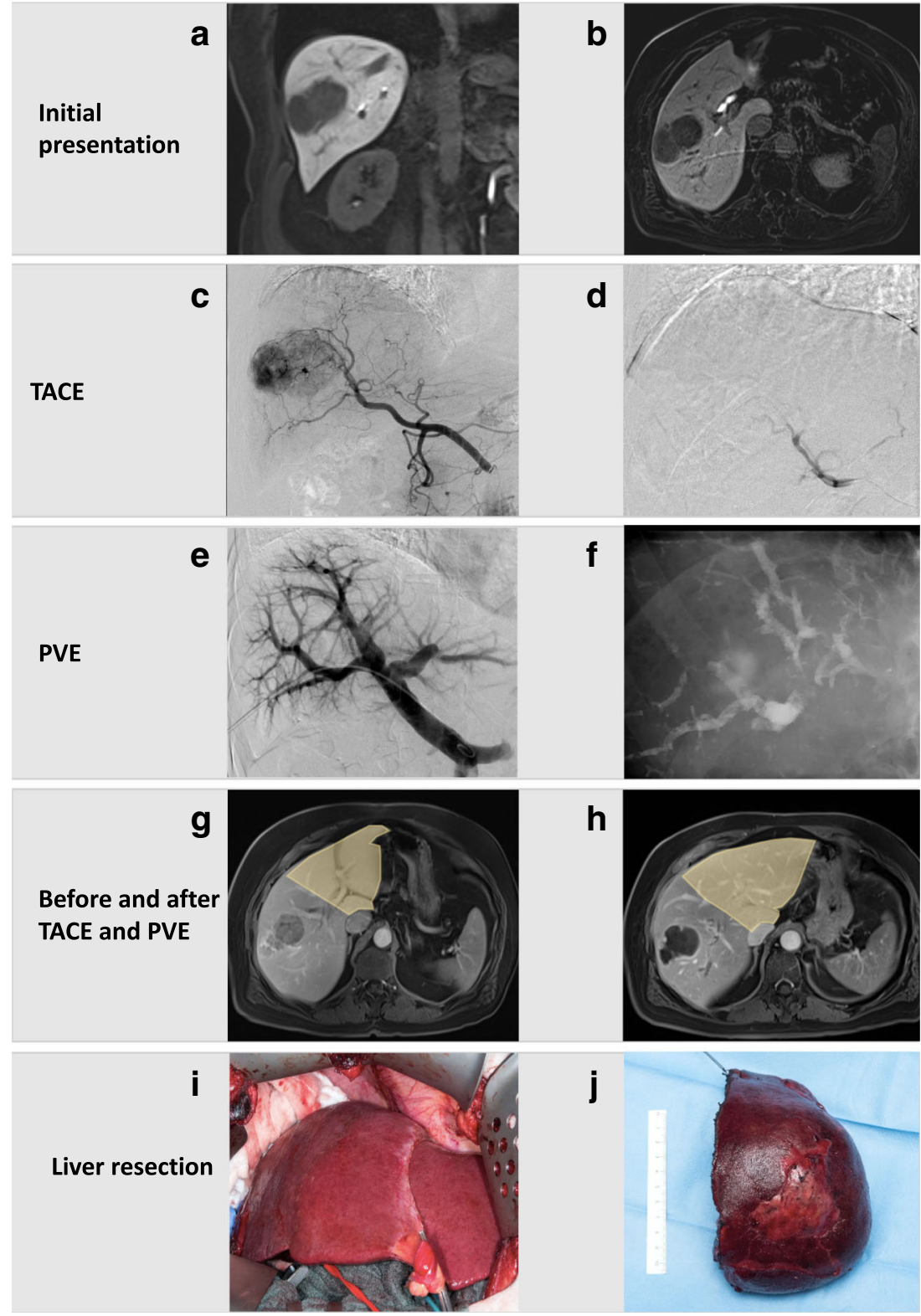

inadequate hypertrophy was lower after PVL (0\%) vs. PVE (4.3\%) [47].

Outcomes of TSH for bilateral CRLM are shown in Table 2. Completion rates for both stages range between 60 and $100 \%$
[48, 50, 51, 53], with FLR hypertrophy between 30 and $60 \%[43$, $48,50,57]$ while postoperative mortality and morbidity rates were between 0 and $15 \%$ [42, 43, 48] and 20-59\% [48-50, 56]. A 3- and 5-year OS of 33-84\% and 32-64\% was reported a

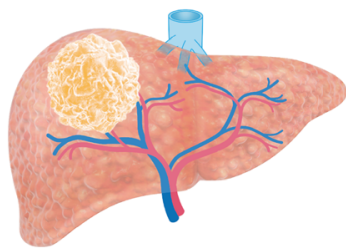

b

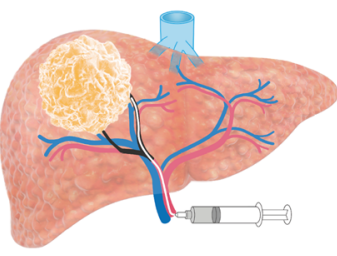

Fig. 4 In patients with large hepatic tumors, underlying liver disease, and small FLR (A), portal vein embolization can be combined with sequential transarterial chemoembolization. For this approach, selective catheterization of the right hepatic artery is performed, then
C

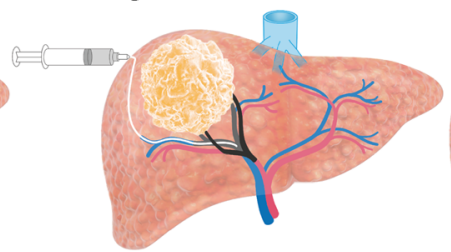

d

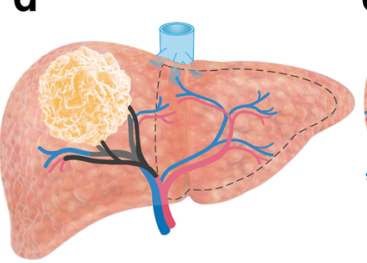

e

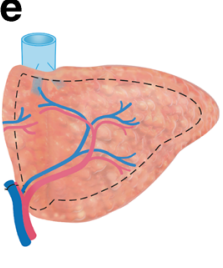

chemotherapy is infused into the selected feeding artery (B). Two to 4 weeks later, this procedure is followed by portal vein embolization $(\mathbf{C})$. After sufficient hypertrophy (D), completion hepatectomy is performed (E) 
Table 1 Studies comparing patients undergoing TACE + PVE with PVE alone

\begin{tabular}{|c|c|c|c|c|c|c|c|}
\hline Reference & Study design & Year & Strategy & Patients $(n)$ & $\begin{array}{l}\text { Volume } \\
\text { increase* } \\
(\%)\end{array}$ & $\operatorname{Time}^{\circ}(\mathrm{d})$ & Resection rate $(\%)$ \\
\hline Aoki et al.[37] & $\mathrm{RCS}$ & 2004 & TACE + PVE & 17 & 22 & $9+25$ & 94 \\
\hline \multirow[t]{2}{*}{ Ogata et al.[38] } & \multirow[t]{2}{*}{ RCS } & \multirow[t]{2}{*}{2006} & TACE + PVE & 18 & 12 & $25+37$ & - \\
\hline & & & PVE & 18 & 8 & 40 & - \\
\hline \multirow[t]{2}{*}{ Yoo et al.[35] } & \multirow[t]{2}{*}{$\mathrm{RCS}$} & \multirow[t]{2}{*}{2011} & TACE + PVE & 71 & 7 & $36+29$ & 96 \\
\hline & & & PVE & 64 & 6 & 31 & 91 \\
\hline \multirow[t]{2}{*}{ Peng et al.[36]** } & \multirow[t]{2}{*}{$\mathrm{RCS}$} & \multirow[t]{2}{*}{2012} & TACE + PVE & 29 & 7 & - & 93 \\
\hline & & & PVE & 25 & 8 & - & 76 \\
\hline \multirow[t]{2}{*}{ Terasawa et al.[34] } & \multirow[t]{2}{*}{$\mathrm{RCS}$} & \multirow[t]{2}{*}{2019} & TACE + PVE & 23 & 43 & $47+47$ & 92 \\
\hline & & & PVE & 28 & 31 & 48 & 68 \\
\hline \multirow[t]{2}{*}{ Park et al.[39] } & \multirow[t]{2}{*}{$\mathrm{RCS}$} & \multirow[t]{2}{*}{2020} & TACE + PVE & 109 & 18 & 75 & - \\
\hline & & & PVE & 38 & 12 & 23 & - \\
\hline
\end{tabular}

$P V E$, portal vein embolization; $R C S$, retrospective case series; $T A C E$, transarterial chemoembolization

*Future liver remnant

**Including secondary liver tumors

${ }^{\circ}$ Time interval between interventions and the surgical resection

$[48,52,56,59,60]$. These data demonstrate comparable morbidity with one-stage hepatectomies and favorable oncologic outcomes for well-selected patients with multiple, bilobar CRLM. More recently, either the first or both steps of TSH have been performed laparoscopically to further diminish surgical trauma $[58,61,62]$. The comparative study by Okumura et al. showed a reduction of postoperative complications (32 vs. $60 \% ; P=$ 0.047 ), a shorter hospital stay ( 9 vs. 16 days; $P=0.013$ ) and earlier administration of chemotherapy (1.6 vs. 2 months; $P=$ 0.039 ) in favor for the laparoscopic approach [62].

A major limitation of conventional TSH, but also one-stage resections with PVE, is the unpredictable long interstage interval [10]. Tumor progression after the first stage was the reason in $80 \%$ and insufficient liver growth in the remaining $20 \%$ for not proceeding to second-stage completion hepatectomy [54, 55, 63-65]. Three or more metastases in the FLR and an age over 70 years were predictive of tumor progression or development of de novo metastases in multivariate analysis [54]. These facts clearly show the importance to protect against tumor

a

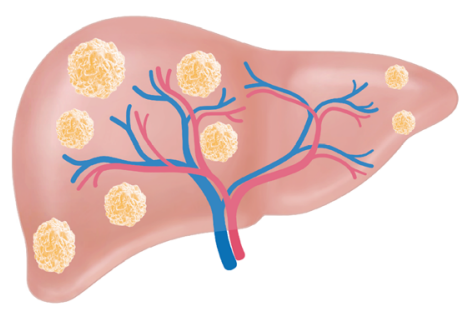

b

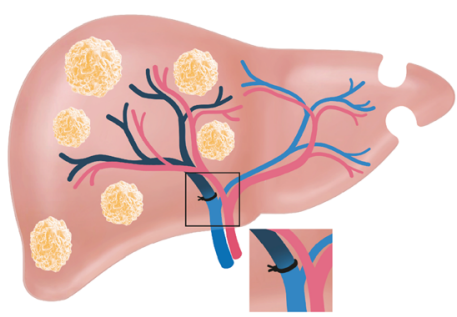

progression during the interstage interval. In order to counteract potential tumor growth, chemotherapy is commonly administered during the interstage interval. Interstage chemotherapy reduced the rate of disease progression without negatively affecting liver hypertrophy $[64,66]$. Pathologic response to chemotherapy was associated with second-stage completion and longer survival [67]. In a series of CRLM from Memorial Sloan-Kettering Cancer Center, disease progression was observed in 34\% after PVE without interstage chemotherapy as compared to $19 \%$ when chemotherapy was administered. OS was improved in patients receiving interstage chemotherapy with 50 versus 24 months [68].

\section{Associating liver partition with portal vein ligation for staged hepatectomy}

Combining PVL and parenchymal transection at the first stage results in an additional growth stimulus of the FLR making

c

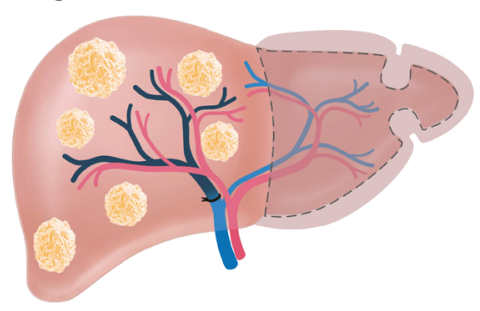

d

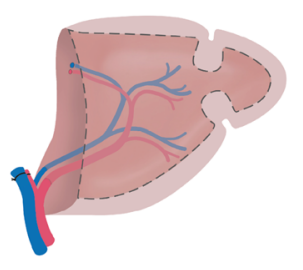

Fig. 5 In case of extensive bilobar tumorload (A), a two-staged approach may be necessary. This can be a conventional TSH with portal vein ligation and clearing of the FLR in a first step (B). After an interstage interval of 4-8 weeks (C), completion hepatectomy is performed after sufficient hypertrophy of the FLR (D) 
Table 2 Perioperative patient outcomes of patients undergoing two-staged hepatectomies

\begin{tabular}{|c|c|c|c|c|c|c|c|c|}
\hline Reference & Year & Patients $(n)$ & PVE/PVL (\%) & Volume increase* $(\%)$ & $\operatorname{Time}^{\circ}(\mathrm{d})$ & Resection rate (\%) & Morbidity (\%) & Mortality (\%) \\
\hline Adam et al. [42] & 2000 & 16 & 44 & - & 120 & 81 & 38 & 15 \\
\hline Jaeck et al. [43] & 2004 & 33 & 100 & 31 & - & 76 & 56 & 0 \\
\hline Tanaka et al. [48] & 2007 & 22 & 73 & 50 & - & 100 & 23 & 0 \\
\hline Wicherts et al. [49] & 2008 & 59 & 78 & - & 126 & 69 & 59 & 7 \\
\hline Homayounfar et al. [50] & 2009 & 24 & 100 & 36 & 55 & 63 & 58 & 5 \\
\hline Tsai et al. [51] & 2010 & 45 & 78 & - & 135 & 78 & 26 & 6 \\
\hline Brouquet et al. [52] & 2011 & 65 & 70 & - & 56 & 72 & 49 & 6 \\
\hline Tsim et al. [53] & 2011 & 38 & 95 & - & - & 87 & 33 & 0 \\
\hline Narita et al. [54] & 2011 & 80 & 95 & - & 92 & 76 & 54 & 0 \\
\hline Muratore et al. [55] & 2012 & 47 & 81 & - & 114 & 77 & 44 & 0 \\
\hline Turrini et al. [56] & 2012 & 42 & 100 & - & 72 & 71 & 20 & 6 \\
\hline Shindoh et al. [57] & 2013 & 144 & 98 & 62 & 34 & 72 & 58 & 6 \\
\hline Fuks et al. [58] & 2015 & 34 & 15 & - & 93 & 76 & 50 & 3 \\
\hline Passot et al. [59] & 2017 & 109 & 73 & - & - & 82 & 27 & 6 \\
\hline
\end{tabular}

$P V E$, portal vein embolization; $P V L$, portal vein ligation

*Future liver remnant

${ }^{\circ}$ Time interval between interventions and the surgical resection

completion hepatectomy feasible in already 1-2 weeks (Fig. 6) [69-73]. This procedure was subsequently termed ALPPS [74]. In the inaugural German report, 25 patients underwent ALPPS for various primary and secondary liver tumors. After a median interstage interval of 9 days, a remarkable FLR hypertrophy of $74 \%$ was observed [69]. This acceleration of liver parenchymal augmentation has created some enthusiasm worldwide as completion rates (i.e., successful progression to stage 2 surgery) exceeded $95 \%$ in most series [75]. In other words, ALPPS was able to markedly increase the number of potentially curative resections compared to PVE and TSH (Fig. 7) [76]. This advantage of ALPPS has led to a universal application for patients with different tumor entities and risk profiles in many centers. The price for that was an initially high perioperative morbidity and mortality [77-84]. Comprehensive analyses based on the international ALPPS registry demonstrated that age $\geq 67$ years, biliary tumors, major interstage complications (Clavien-Dindo $\geq 3 \mathrm{~b}$ ), and elevated bilirubin and creatinine before stage 2 were associated with 90-day or in-hospital mortality [85, 86]. Most centers subsequently refined their patient selection and were more cautious with proceeding with stage 2 surgery in case predictors for short-term mortality were present $[80,87]$. In addition, technical modifications have led to a less invasivestage 1 surgery with the goal to enable an uncompromised liver parenchymal hypertrophy in the interstage interval in many centers. These technical modifications include partial-ALPPS [88, 89], laparoscopic ALPPS [90], tourniquet ALPPS [91], and miniALPPS [92]. An analysis form the international ALPPS registry found the combination of risk adjustment in patient selection and technique resulted in a significant decrease in early morbidity and mortality to levels which are widely accepted for major liver surgery [87]. With accumulating experience in some expert centers, ALPPS has been re-considered for nonCRLM tumor entities like neuroendocrine liver metastases [93], intrahepatic CC [94], HCC [95, 96], and PHC [97] in selected cases. In an attempt to define reference values for ALPPS, a recent benchmark analysis focusing on a low-risk a
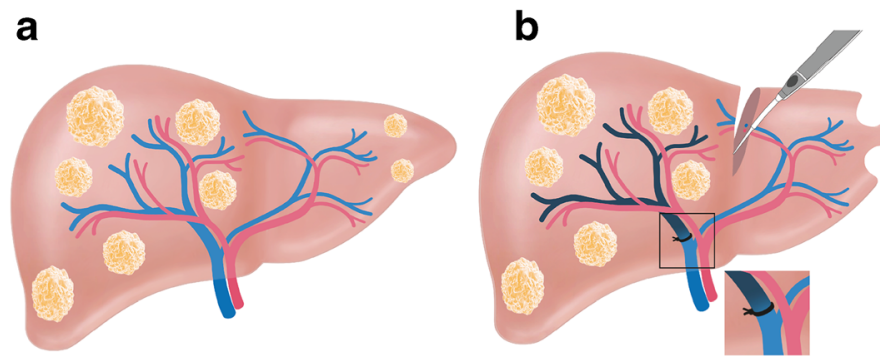

Fig. 6 As an alternative to a conventional TSH, associating liver partition and portal vein ligation for staged hepatectomy (ALPPS) can be performed for extensive bilobar tumorload (A). In the first stage portal vein

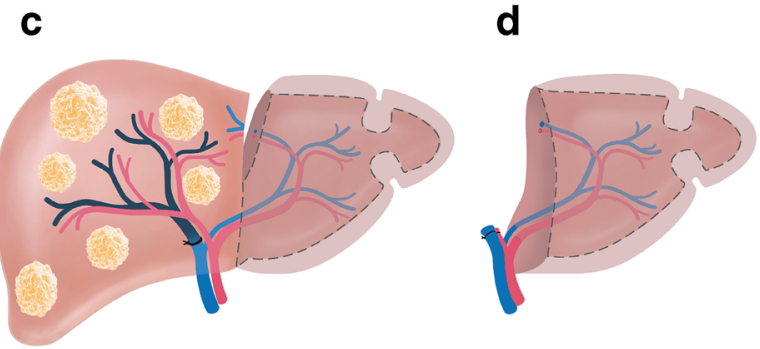

ligation, clearing of the FLR and liver transection is performed (B). After an interstage interval of 1-2 weeks (C), sufficient hypertrophy is observed and completion hepatectomy is performed (D) 
Fig. 7 Clinical case of associating liver partition and portal vein ligation for staged hepatectomy (University of Zurich). We present the case of a 61-year-old patient with synchronous bilobar colorectal liver metastases (A/B). After neo-adjuvant therapy with folinic acid, oxaliplatin, fluorouracil (FOLFOX), and panitumumab, a liver first approach was chosen $(\mathbf{C} / \mathbf{D})$. Due to a small sFLR of $18 \%(\mathbf{E})$, we decided to perform a two-staged hepatectomy. In the first stage, clearing of the left hemi-liver with four atypical resections, $50 \%$ parenchymal transection, and rightsided portal vein ligation were performed (C). Eight days later, and after an increase of the sFLR to $29 \%$ (F), we performed completion hepatectomy $(\mathbf{G})(\mathbf{H})$. Two months after ALPPS, the patient was scheduled for adjuvant chemotherapy

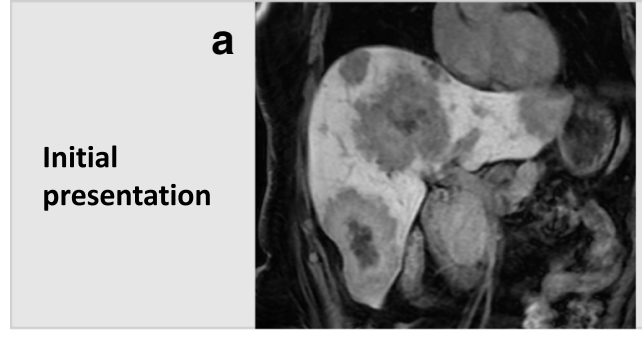

b
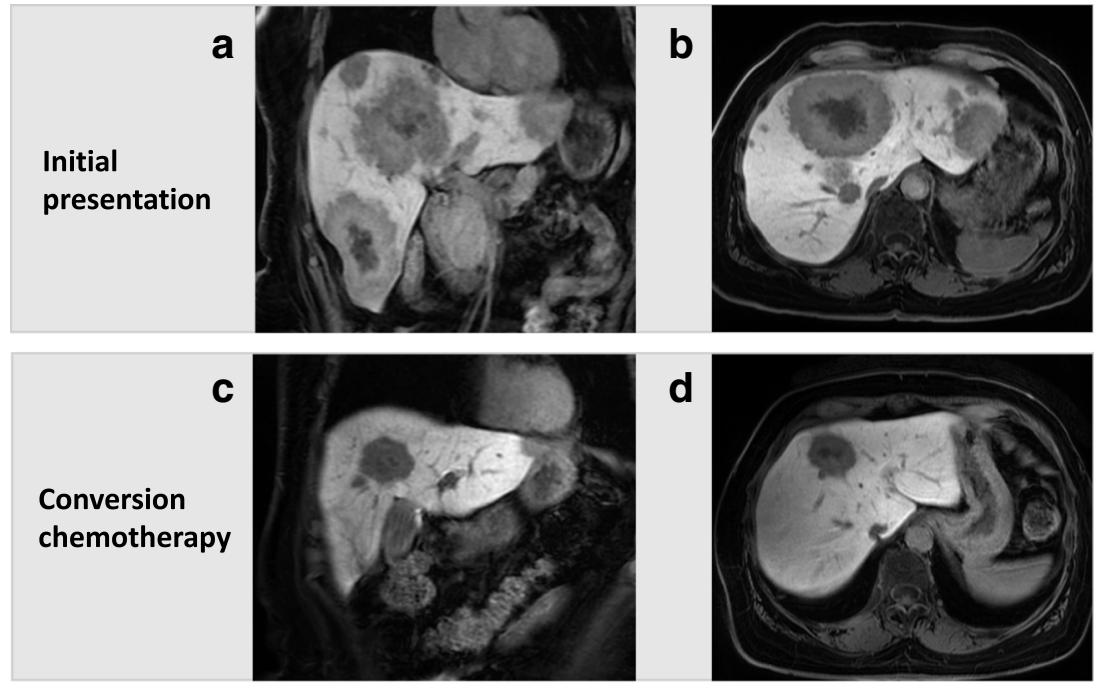

d
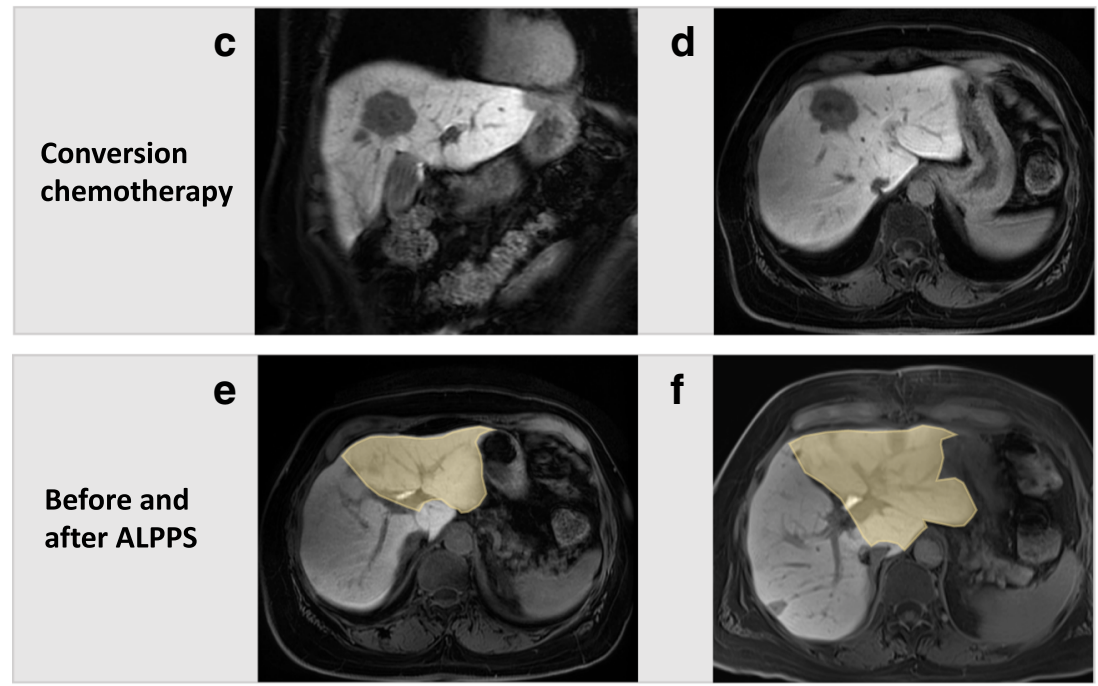

f
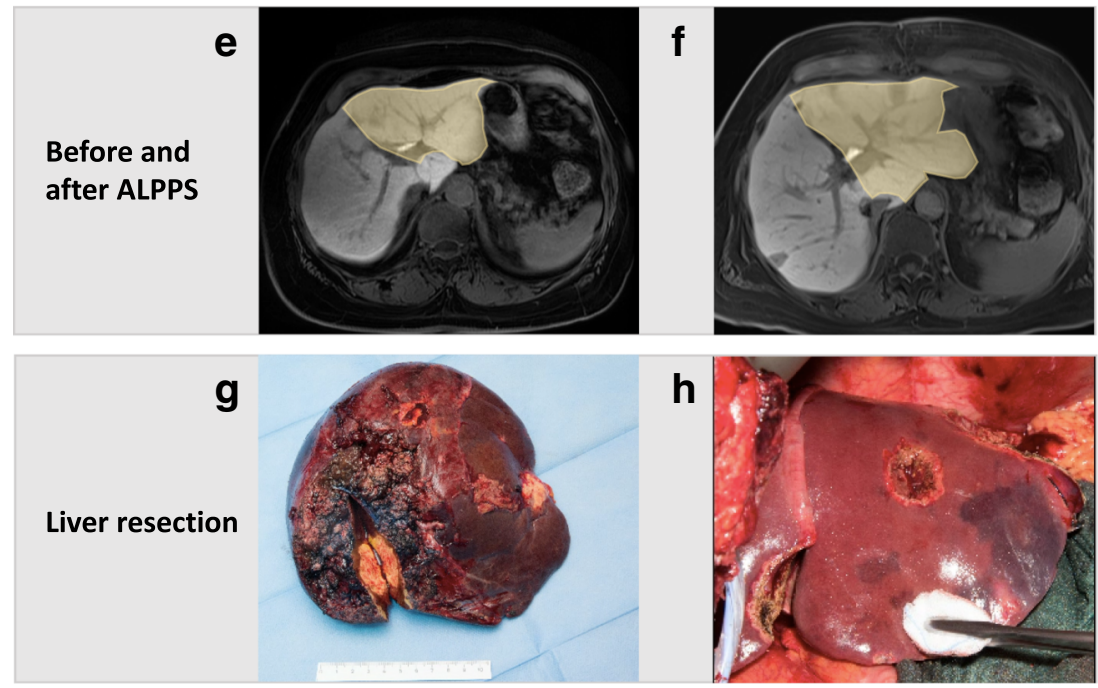

population with CRLM found a 90-day mortality rate $\leq 5 \%$, major complications (Clavien-Dindo grade $\geq 3 \mathrm{a}$ ) $\leq 65 \%$, postoperative liver failure after stage $2: \leq 5 \%$, and completion of stage 2 surgery $\geq 96 \%$ [98]. Of note, in this population, the FLR increased from $0.21 \%$ (SD 0.12) to 0.41 (SD 0.09) after a median interstage interval of 13 days [98].

A Scandinavian multicenter RCT comparing ALPPS and TSH in 100 patients confirms the evidence from single, retrospective series and registry data that ALPPS is associated with significantly higher resection rates (ALPPS, $92 \%$ vs. TSH, $57 \%$ ). In this trial, patients with CRLM and sFLR $<30 \%$ were randomized into ALPPS versus TSH. The ALPPS group had a significant greater volume increase of $68 \%$ vs. $36 \%$, while stage 2 was performed after 11 days in the ALPPS group compared to 43 days in the TSH group. Of note, 12 patients that failed to reach an sFLR of $\geq 30 \%$ in the TSH arm were successfully treated with rescue ALPPS. Interestingly, the study found no difference in major complications (ALPPS, $43 \%$ vs. TSH, $43 \%$ ) and 90-day mortality (ALPPS, $8.3 \%$ vs. THS, $6.1 \%$ ) [73]. The survival analysis of the RCT furthermore showed an improved median OS of 46 months for patients randomized to ALPPS versus 26 months randomized to TSH [99]. Looking at the hypertrophy induced by ALPPS in more detail, two metaanalyses found significantly greater hypertrophy for the ALPPS group compared to PVE. The study by Eshmuminov et al. included two studies and found an FLR increase of $76 \%$ in the ALPPS group versus $37 \%$ in the PVE groups $(P<0 \cdot 001)$ [75]. A more recent meta-analysis found that ALPPS induced a greater FLR increase compared to PVE (RR 6.30; 95\% CI, 3.97-8.64) and conventional TSH (RR 3.27; 95\%CI, 1.63 4.91) [100]. Studies comparing ALPPS versus conventional TSH with PVE and PVL are shown in Table 3.

\section{Resection and partial liver segment 2/3 transplantation with delayed total hepatectomy and associated concepts}

This innovative two-stage concept, introduced by the Oslo group in 2015, combines regeneration of a left lateral partial 
Table 3 Comparative studies evaluating patient outcomes for PVE and ALPPS

\begin{tabular}{|c|c|c|c|c|c|c|c|}
\hline Reference & Year & Study design & Strategy & Patients $(n)$ & Volume increase* $(\%)$ & $\operatorname{Time}^{\circ}(\mathrm{d})$ & Resection rate $(\%)$ \\
\hline \multirow[t]{2}{*}{ Knoefel et al. [70] } & \multirow[t]{2}{*}{2012} & \multirow[t]{2}{*}{$\mathrm{RCS}$} & ALPPS & 7 & 63 & 8 & 100 \\
\hline & & & PVE & 15 & 37 & 35 & 80 \\
\hline \multirow[t]{2}{*}{ Tanaka et al. [83] } & \multirow[t]{2}{*}{2015} & \multirow[t]{2}{*}{$\mathrm{RCS}$} & ALPPS & 10 & 54 & - & - \\
\hline & & & PVE & 54 & 19 & - & - \\
\hline \multirow[t]{2}{*}{ Croome et al. [71] } & \multirow[t]{2}{*}{2015} & \multirow[t]{2}{*}{$\mathrm{RCS}$} & ALPPS & 15 & $84^{\circ \circ}$ & 8 & 100 \\
\hline & & & PVE & 53 & $36^{\circ \circ}$ & 40 & 79 \\
\hline Schadde et al. [82] & 2015 & $\mathrm{RCS}$ & ALPPS & 320 & $100^{\circ \circ}$ & 14 & 98 \\
\hline \multirow[t]{2}{*}{ Ratti et al. [84] } & \multirow[t]{2}{*}{2015} & \multirow[t]{2}{*}{$\mathrm{RCS}$} & ALPPS & 12 & 47 & 11 & 100 \\
\hline & & & PVE/PVL & 36 & 41 & 31 & 94 \\
\hline \multirow[t]{2}{*}{ Chia et al. [72] } & \multirow[t]{2}{*}{2017} & \multirow[t]{2}{*}{$\mathrm{RCS}$} & ALPPS & 10 & 48 & - & 80 \\
\hline & & & PVE/PVL & 29 & 12 & 46 & 59 \\
\hline \multirow[t]{2}{*}{ Sandström et al. [73] } & \multirow[t]{2}{*}{2018} & \multirow[t]{2}{*}{$\mathrm{RCT}$} & ALPPS & 48 & 68 & 11 & 92 \\
\hline & & & PVE/PVL & 49 & 36 & 43 & 57 \\
\hline \multirow[t]{2}{*}{ Chan et al. [95] } & \multirow[t]{2}{*}{2019} & \multirow[t]{2}{*}{$\mathrm{RCS}$} & ALPPS & 46 & 48 & 7 & 98 \\
\hline & & & PVE & 102 & 38 & 48 & 68 \\
\hline
\end{tabular}

$A L P P S$, associating liver partition and portal vein ligation for staged hepatectomy; $P V E$, portal vein embolization; $R C S$, retrospective case series; RCT, Randomized controlled trial

*Future liver remnant

${ }^{\circ}$ Time interval between interventions and the surgical resection

${ }^{\circ}$ Standardized future liver remnant.

liver graft followed by delayed resection of the native, metastatic liver [101]. In a first stage, segments $1-3$ are resected and a partial segment $2-3$ graft from a deceased donor is transplanted orthotopically. In addition, the right portal vein is ligated in this stage directing the portal flow to the graft. After sufficient regeneration of the allograft, the native right hemi-liver is resected (Fig. 8). In other words, the deportalized native liver is turning its function into an auxiliary liver enabling the left lateral graft to regenerate in the interstage interval. Compared to whole organ liver transplantation, the RAPID procedure has the advantage that the precious donor pool is not affected as the extended right liver graft can be transplanted to adult patients without significant disadvantage [102]. To evaluate the clinical benefits of the RAPID procedure including step two completion rate and the overall survival, the Oslo group is currently recruiting patients for their prospective study (NCT02215889). To date, the experience is limited to 3 transplanted patients with one patient disease-free after 5.5 years, one alive after 2 years with lung recurrence after 12 months, and one mortality due to graft hepatic artery thrombosis 40 days post-RAPID [103].

Addressing the lack of split policy and low organ donation rates, Königsrainer et al. proposed living donor (LD) RAPID procedure [104]. To our knowledge, 8 LDRAPID have been performed so far, 5 in Germany, 2 in Italy, and 1 in Belgium. Of note, three patients are alive and tumor-free after 6-18 months [103]. A prospective biinstitutional German trial (University of Tübingen and University of Jena) currently evaluates the feasibility, safety, and efficacy of LD-RAPID for non-resectable CRLM with overall survival at 36 months as primary endpoint (NCT03488953) [105]. a
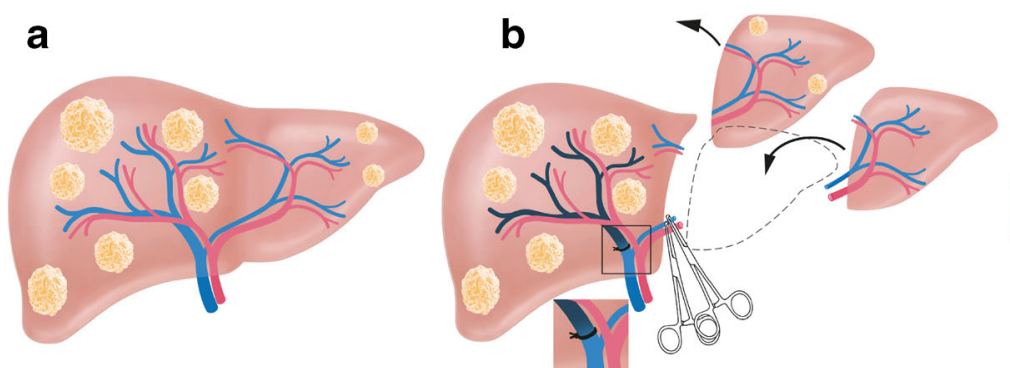

C

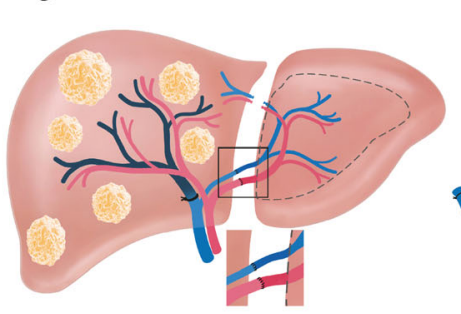

d

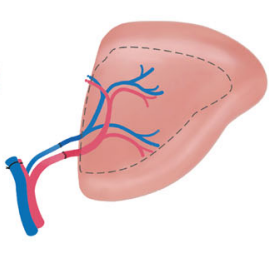

Fig. 8 The RAPID approach combines resection with partial liver segment $2 / 3$ transplantation and delayed total hepatectomy for bilobar liver metastases (A). In a first step, segments 1-3 are removed, in combination with right portal vein ligation (B) and transplantation of a left partial allograft $(\mathbf{C})$. After sufficient regeneration, the native right hemi-liver is removed in a second step (D) 
Fig. 9 Clinical case of RAPID approach in a cirrhotic patient with portal hypertension and hepatocellular carcinoma (Ankara University School of Medicine) [106]. After removing segments 1-3 (A/B), a small left lobe graft (segments 2, 3, 4; graft-torecipient weight ratio 0.35 ) was transplanted $(\mathbf{C})$. Due to the portal hypertension, inflow modification was necessary and a

hemiportocaval shunt was created that re-routed approximately twothirds of portal flow to the inferior vena cava decreasing the portal pressure from 24 to $14 \mathrm{mmHg}$. After 22 days, hepatobiliary scintigraphy showed an almost $70 \%$ functional shift to the left lobe graft (D), and there was a 56\% graft volume hypertrophy $(\mathbf{E}, \mathbf{F})$. In the second stage, the right hemi-liver was removed, with closure of the hemiportocaval shunt. To control potential portal hyperflow and arterial buffer response, splenic artery ligation was added at the end of the operation. The patient recovered without liver failure and is without tumor recurrence almost 2 years after the 1st-stage operation $(\mathbf{G} / \mathbf{H})$
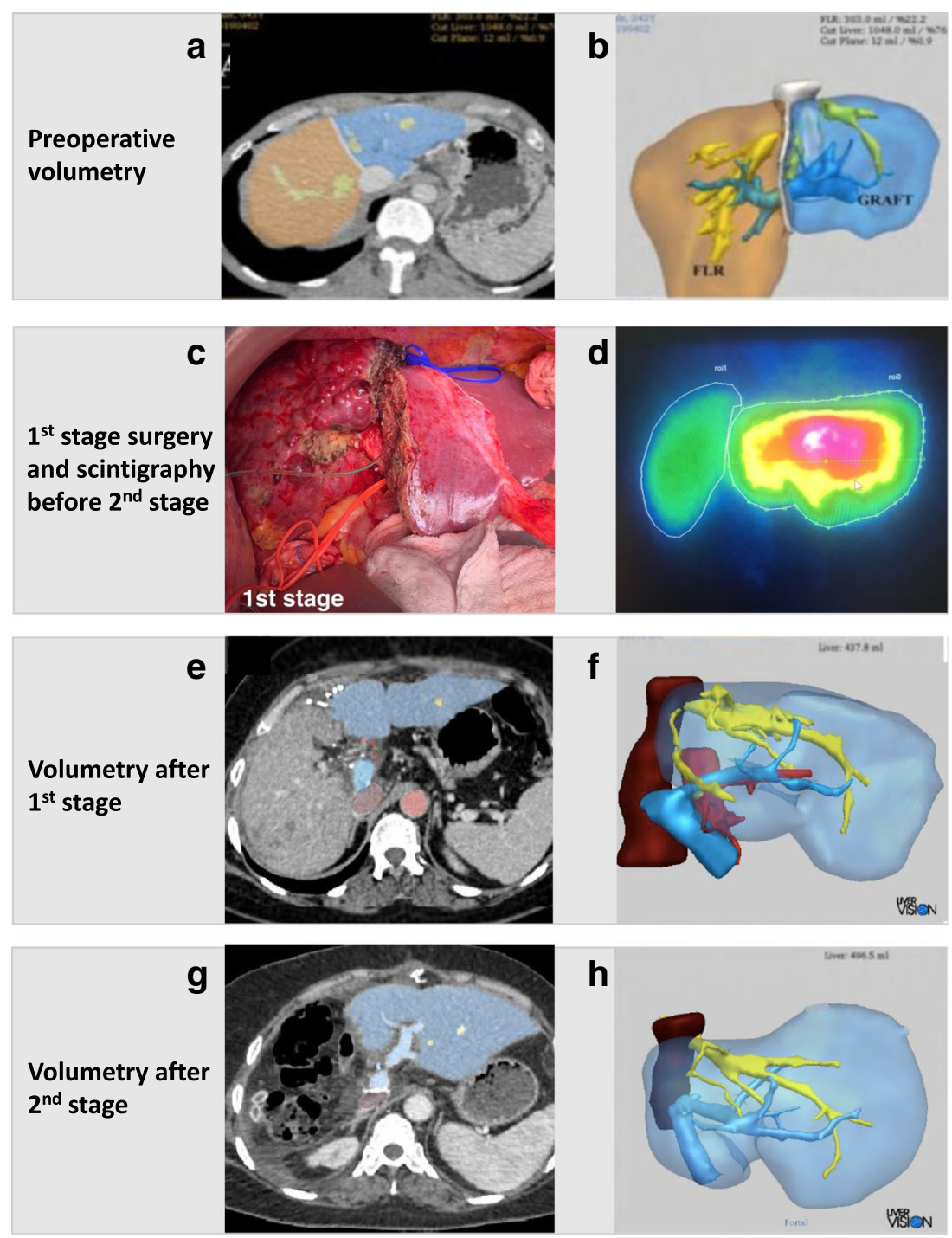

Recently, the RAPID procedure has also been described in a patient with liver cirrhosis, portal hypertension (PHT), and a $3 \mathrm{~cm} \mathrm{HCC}$, potentially extending the indication to selected patients with underlying liver disease [106]. Balci et al. used a small left lobe graft (graft-to-recipient weight ratio 0.35 ) for LD-liver transplantation. In order to overcome PHT in the cirrhotic setting, inflow modification was necessary to provide an adequate portal- and hepatic artery flow to the partial graft, while decreasing portal pressure to prevent early allograft dysfunction. A hemiportacaval shunt was created, which rerouted two-thirds of the portal flow to the inferior vena cava, decreasing portal pressure from 24 to $14 \mathrm{mmHg}$ in the first stage. Twenty-two days after the first operation, there was a $56 \%$ graft volume increase and a functional shift of over $60 \%$ to the partial graft. At the end of second operation, the hemiportacaval shunt was closed and the splenic artery ligated in order to control for potential portal hyperflow and arterial buffer response. The patient recovered without liver failure and is without tumor recurrence almost 2 years after the operation (Fig. 9) [106].

Taking the concept of RAPID further, the Bologna group has recently reported the transplantation of such graft heterotopically into the splenic fossa $[107,108]$. This procedure is coined "heteRotopic trAnsplantation of segments 2 and 3 using the splenic Vein and Artery after $\underline{\text { Splenectomy }}$ and with delayed total hepatectomy" (RAVAS) and necessitates a splenectomy before partial liver transplantation can be performed. The authors describe one case of a 40-year-old male with synchronous, unresectable CRLM. The original plan was to perform a TSH with cleaning of the FLR and subsequent PVE. This plan, however, did not succeed as the patient developed a severe bile leak and could not undergo completion hepatectomy. The authors utilized a left lateral graft, which was rejected for pediatric liver transplantation. In contrast to RAPID, the authors placed a tourniquet on the main PV of the native liver to modulate portal flow to the 
graft. After an interstage interval of 2 weeks, the graft-to-body weight ratio successfully augmented from 0.6 to 1 and native hepatectomy became feasible. At 8 months after RAVAS, the patient is in good health condition with no evidence of tumor recurrence. A potential advantage of this procedure is to avoid manipulation of the native, tumor-bearing liver. In the past, however, heterotopic liver transplantation has turned out to be prone to vascular complications with kinking of vessels and particularly an unfavorable outflow situation with a high risk of Budd Chiari syndrome [109].

Common to RAPID and associated concepts is that they may increase the employment of liver transplantation in metastatic disease in selected cases. The major advantage is that small segment $2 / 3$ grafts can be augmented to a fully functioning graft with the temporary help of an auxiliary, deportalized native liver. These procedures probably rank among the most complex procedures in liver surgery requiring profound experience of surgeons and the whole care team in extensive liver surgery and living donor liver transplantation.

\section{Conclusion}

Since the introduction of the first liver parenchyma augmentation-assisted techniques of PVE in the 1980s, this field has tremendously evolved meanwhile creating an own established niche in liver surgery. Utilizing the unique ability of the liver to regenerate enables most extended resections with leaving only a very small liver remnant behind. Nevertheless, most of the techniques rely on portal vein occlusion, but more recently inclusion of parenchymal splitting, hepatic vein occlusion, and partial liver transplantation has extended the technical armamentarium to induce liver parenchymal augmentation prior hepatectomy. Safely accomplishing major and ultimately total hepatectomy by this means requires an integration into a meaningful oncological concept. The availability of highly effective chemotherapeutic regimens in the neo-adjuvant, interstage, and adjuvant setting underlines an aggressive surgical approach in the given tumor setting to convert formerly "palliative" disease into a curative and sometimes in a "chronic" disease.

Author's contributions PCM, ML, HP: study design, literature review, writing the manuscript; PAC, DB, CEO, EOK: study design, critical revision of the manuscript.

Funding Open Access funding provided by Universität Zürich. The study was funded by institutional means.

\section{Declarations}

Ethics approval All procedures performed in studies involving human participants were in accordance with the ethical standards of the institutional and/or national research committee and with the 1964 Helsinki declaration and its later amendments or comparable ethical standards.

Conflict of interest The authors declare that they have no conflict of interest.

Open Access This article is licensed under a Creative Commons Attribution 4.0 International License, which permits use, sharing, adaptation, distribution and reproduction in any medium or format, as long as you give appropriate credit to the original author(s) and the source, provide a link to the Creative Commons licence, and indicate if changes were made. The images or other third party material in this article are included in the article's Creative Commons licence, unless indicated otherwise in a credit line to the material. If material is not included in the article's Creative Commons licence and your intended use is not permitted by statutory regulation or exceeds the permitted use, you will need to obtain permission directly from the copyright holder. To view a copy of this licence, visit http://creativecommons.org/licenses/by/4.0/.

\section{References}

1. Petrowsky H, Fritsch R, Guckenberger M et al (2020) Modern therapeutic approaches for the treatment of malignant liver tumours. Nat Rev Gastroenterol Hepatol 17(12):755-772. https:// doi.org/10.1038/s41575-020-0314-8

2. Clavien P-A, Petrowsky H, DeOliveira ML, Graf R (2007) Strategies for safer liver surgery and partial liver transplantation. N Engl J Med 356:1545-1559. https://doi.org/10.1056/ NEJMra065156

3. Rous P, Larimore LD (1920) Relation of the portal blood to liver maintenance : a demonstration of liver atrophy conditional on compensation. J Exp Med 31:609. https://doi.org/10.1084/jem. 31.5.609

4. Honjo I, Suzuki T, Ozawa K et al (1975) Ligation of a branch of the portal vein for carcinoma of the liver. Am J Surg 130(3):296302 https://pubmed.ncbi.nlm.nih.gov/170837/. Accessed 14 Oct 2020

5. Makuuchi M, Takayasu K, Takuma T et al (1984) Preoperative transcatheter embolization of the portal venous branch for patients receiving extended lobectomy due to the bile duct carcinoma. J Jpn Soc Clin Surg 45:14-21

6. Makuuchi M, Thai BL, Takayasu K et al (1990) Preoperative portal embolization to increase safety of major hepatectomy for hilar bile duct carcinoma: a preliminary report. Surgery 107:521527

7. Hemming AW, Reed AI, Howard RJ et al (2003) Preoperative portal vein embolization for extended hepatectomy. Ann Surg 237:686-691; discussion 691-693. https://doi.org/10.1097/01. SLA.0000065265.16728.C0

8. Azoulay D, Castaing D, Krissat J et al (2000) Percutaneous portal vein embolization increases the feasibility and safety of major liver resection for hepatocellular carcinoma in injured liver. Ann Surg 232:665-672. https://doi.org/10.1097/00000658200011000-00008

9. Elias D, Ouellet J-F, De Baère T et al (2002) Preoperative selective portal vein embolization before hepatectomy for liver metastases: long-term results and impact on survival. Surgery 131:294-299. https://doi.org/10.1067/msy.2002.120234

10. Abulkhir A, Limongelli P, Healey AJ et al (2008) Preoperative portal vein embolization for major liver resection: a meta-analysis. 
Ann Surg 247:49-57. https://doi.org/10.1097/SLA. 0b013e31815f6e 5b

11. Wajswol E, Jazmati T, Contractor S, Kumar A (2018) Portal vein embolization utilizing n-butyl cyanoacrylate for contralateral lobe hypertrophy prior to liver resection: a systematic review and metaanalysis. Cardiovasc Intervent Radiol 41:1302-1312. https://doi. org/10.1007/s00270-018-1964-6

12. Ribero D, Abdalla EK, Madoff DC et al (2007) Portal vein embolization before major hepatectomy and its effects on regeneration, resectability and outcome. Br J Surg 94:1386-1394. https://doi. org/10.1002/bjs.5836

13. Kishi Y, Madoff DC, Abdalla EK et al (2008) Is embolization of segment 4 portal veins before extended right hepatectomy justified? Surgery 144:744-751. https://doi.org/10.1016/j.surg.2008. 05.015

14. Björnsson B, Hasselgren K, Røsok B et al (2020) Segment 4 occlusion in portal vein embolization increase future liver remnant hypertrophy - a Scandinavian cohort study. Int J Surg 75:60-65. https://doi.org/10.1016/j.jisu.2020.01.129

15. Nagino M, Kamiya J, Kanai M et al (2000) Right trisegment portal vein embolization for biliary tract carcinoma: technique and clinical utility. Surgery 127:155-160. https://doi.org/10.1067/msy. 2000.101273

16. van Gulik TM, van den Esschert JW, de Graaf W et al (2008) Controversies in the use of portal vein embolization. Dig Surg 25:436-444. https://doi.org/10.1159/000184735

17. Guiu B, Chevallier P, Denys A et al (2016) Simultaneous transhepatic portal and hepatic vein embolization before major hepatectomy: the liver venous deprivation technique. Eur Radiol 26: 4259-4267. https://doi.org/10.1007/s00330-016-4291-9

18. Laurent C, Fernandez B, Marichez A et al (2020) Radiological simultaneous portohepatic vein embolization (RASPE) Before major hepatectomy: a better way to optimize liver hypertrophy compared to portal vein embolization. Ann Surg 272:199-205. https://doi.org/10.1097/SLA.0000000000003905

19. Balci D, Kirimker EO (2020) Hepatic vein in living donor liver transplantation. Hepatobiliary Pancreat Dis Int 19:318-323. https://doi.org/10.1016/j.hbpd.2020.07.002

20. Madoff DC, Odisio BC, Schadde E et al (2020) Improving the safety of major resection for hepatobiliary malignancy: portal vein embolization and recent innovations in liver regeneration strategies. Curr Oncol Rep 22:59. https://doi.org/10.1007/s11912-02000922-X

21. Schadde E, Guiu B, Deal R et al (2019) Simultaneous hepatic and portal vein ligation induces rapid liver hypertrophy: a study in pigs. Surgery 165:525-533. https://doi.org/10.1016/j.surg.2018. 09.001

22. Hwang S, Lee S-G, Ko G-Y et al (2009) Sequential preoperative ipsilateral hepatic vein embolization after portal vein embolization to induce further liver regeneration in patients with hepatobiliary malignancy. Ann Surg 249:608-616. https://doi.org/10.1097/ SLA.0b013e31819ecc5c

23. Guiu B, Quenet F, Escal L et al (2017) Extended liver venous deprivation before major hepatectomy induces marked and very rapid increase in future liver remnant function. Eur Radiol 27: 3343-3352. https://doi.org/10.1007/s00330-017-4744-9

24. Le Roy B, Perrey A, Fontarensky M et al (2017) Combined Preoperative portal and hepatic vein embolization (biembolization) to Improve liver regeneration before major liver resection: a preliminary report. World J Surg 41:1848-1856. https://doi.org/10.1007/s00268-017-4016-5

25. Le Roy B, Gallon A, Cauchy F et al (2020) Combined biembolization induces higher hypertrophy than portal vein embolization before major liver resection. HPB 22:298-305. https:// doi.org/10.1016/j.hpb.2019.08.005
26. Panaro F, Giannone F, Riviere B et al (2019) Perioperative impact of liver venous deprivation compared with portal venous embolization in patients undergoing right hepatectomy: preliminary results from the pioneer center. Hepatobiliary Surg Nutr 8:329-337. https://doi.org/10.21037/hbsn.2019.07.06

27. Kobayashi K, Yamaguchi T, Denys A et al (2020) Liver venous deprivation compared to portal vein embolization to induce hypertrophy of the future liver remnant before major hepatectomy: a single center experience. Surgery 167:917-923. https://doi.org/ 10.1016/j.surg.2019.12.006

28. Hocquelet A, Sotiriadis C, Duran R et al (2018) Preoperative portal vein embolization alone with biliary drainage compared to a combination of simultaneous portal vein, right hepatic vein embolization and biliary drainage in Klatskin tumor. Cardiovasc Intervent Radiol 41:1885-1891. https://doi.org/10.1007/s00270018-2075-0

29. Heil J, Schadde E (2020) Simultaneous portal and hepatic vein embolization before major liver resection. Langenbeck's Arch Surg. https://doi.org/10.1007/s00423-020-01960-6

30. Deshayes E, Piron L, Bouvier A et al (2020) Study protocol of the HYPER-LIV01 trial: a multicenter phase II, prospective and randomized study comparing simultaneous portal and hepatic vein embolization to portal vein embolization for hypertrophy of the future liver remnant before major hepatectomy for colo-rectal liver metastases. BMC Cancer 20:574. https://doi.org/10.1186/s12885020-07065-Z

31. Goebel J, Sulke M, Lazik-Palm A et al (2017) Factors associated with contralateral liver hypertrophy after unilateral radioembolization for hepatocellular carcinoma. PLoS One 12: e0181488. https://doi.org/10.1371/journal.pone.0181488

32. Farges O, Belghiti J, Kianmanesh R et al (2003) Portal vein embolization before right hepatectomy: prospective clinical trial. Ann Surg 237:208-217. https://doi.org/10.1097/01.SLA.0000048447. 16651.7B

33. Lencioni R, de Baere T, Soulen MC et al (2016) Lipiodol transarterial chemoembolization for hepatocellular carcinoma: a systematic review of efficacy and safety data. Hepatology 64: 106-116. https://doi.org/10.1002/hep.28453

34. Terasawa M, Allard M-A, Golse N et al (2020) Sequential transcatheter arterial chemoembolization and portal vein embolization versus portal vein embolization alone before major hepatectomy for patients with large hepatocellular carcinoma: an intent-to-treat analysis. Surgery 167:425-431. https://doi.org/10.1016/j.surg. 2019.09.023

35. Yoo H, Kim JH, Ko G-Y et al (2011) Sequential transcatheter arterial chemoembolization and portal vein embolization versus portal vein embolization only before major hepatectomy for patients with hepatocellular carcinoma. Ann Surg Oncol 18:12511257. https://doi.org/10.1245/s10434-010-1423-3

36. Peng PD, Hyder O, Bloomston M et al (2012) Sequential intraarterial therapy and portal vein embolization is feasible and safe in patients with advanced hepatic malignancies. HPB 14:523-531. https://doi.org/10.1111/j.1477-2574.2012.00492.x

37. Aoki T, Imamura H, Hasegawa K et al (2004) Sequential preoperative arterial and portal venous embolizations in patients with hepatocellular carcinoma. Arch Surg 139:766-774. https://doi. org/10.1001/archsurg.139.7.766

38. Ogata S, Belghiti J, Farges O et al (2006) Sequential arterial and portal vein embolizations before right hepatectomy in patients with cirrhosis and hepatocellular carcinoma. Br J Surg 93:10911098. https://doi.org/10.1002/bjs.5341

39. Park GC, Lee SG, Yoon YI et al (2020) Sequential transcatheter arterial chemoembolization and portal vein embolization before right hemihepatectomy in patients with hepatocellular carcinoma. Hepatobiliary Pancreat Dis Int 19:244-251. https://doi.org/10. 1016/j.hbpd.2020.04.008 
40. Glantzounis GK, Tokidis E, Basourakos S-P et al (2017) The role of portal vein embolization in the surgical management of primary hepatobiliary cancers. A systematic review. Eur J Surg Oncol 43: 32-41. https://doi.org/10.1016/j.ejso.2016.05.026

41. Kim HK, Chung YH, Song BC et al (2001) Ischemic bile duct injury as a serious complication after transarterial chemoembolization in patients with hepatocellular carcinoma. $\mathrm{J}$ Clin Gastroenterol 32:423-427. https://doi.org/10.1097/ 00004836-200105000-00013

42. Adam R, Laurent A, Azoulay D et al (2000) Two-stage hepatectomy: a planned strategy to treat irresectable liver tumors. Ann Surg 232:777-785. https://doi.org/10.1097/00000658200012000-00006

43. Jaeck D, Oussoultzoglou E, Rosso E et al (2004) A two-stage hepatectomy procedure combined with portal vein embolization to achieve curative resection for initially unresectable multiple and bilobar colorectal liver metastases. Ann Surg 240:1037-1049; discussion 1049-1051. https://doi.org/10.1097/01.sla.0000145965. 86383.89

44. Kianmanesh R, Farges O, Abdalla EK et al (2003) Right portal vein ligation: a new planned two-step all-surgical approach for complete resection of primary gastrointestinal tumors with multiple bilateral liver metastases. J Am Coll Surg 197:164-170. https://doi.org/10.1016/S1072-7515(03)00334-X

45. Capussotti L, Muratore A, Baracchi F et al (2008) Portal vein ligation as an efficient method of increasing the future liver remnant volume in the surgical treatment of colorectal metastase. Arch Surg 143:978-982; discussion 982. https://doi.org/10.1001/ archsurg.143.10.978

46. Kianmanesh R, Sauvanet A, Hentic O et al (2008) Two-step surgery for synchronous bilobar liver metastases from digestive endocrine tumors: a safe approach for radical resection. Ann Surg 247:659-665. https://doi.org/10.1097/SLA.0b013e31816a7061

47. Isfordink CJ, Samim M, Braat MNGJA et al (2017) Portal vein ligation versus portal vein embolization for induction of hypertrophy of the future liver remnant: a systematic review and metaanalysis. Surg Oncol 26:257-267. https://doi.org/10.1016/j. suronc.2017.05.001

48. Tanaka K, Shimada H, Matsuo K et al (2007) Remnant liver regeneration after two-stage hepatectomy for multiple bilobar colorectal metastases. Eur J Surg Oncol 33:329-335. https://doi.org/ 10.1016/j.ejso.2006.10.038

49. Wicherts DA, Miller R, de Haas RJ et al (2008) Long-term results of two-stage hepatectomy for irresectable colorectal cancer liver metastases. Ann Surg 248:994-1005. https://doi.org/10.1097/ SLA.0b013e3181907fd9

50. Homayounfar K, Liersch T, Schuetze G et al (2009) Two-stage hepatectomy (R0) with portal vein ligation-towards curing patients with extended bilobular colorectal liver metastases. Int J Color Dis 24:409-418. https://doi.org/10.1007/s00384-0080620-z

51. Tsai S, Marques HP, de Jong MC et al (2010) Two-stage strategy for patients with extensive bilateral colorectal liver metastases. HPB 12:262-269. https://doi.org/10.1111/j.1477-2574.2010. 00161.x

52. Brouquet A, Abdalla EK, Kopetz S et al (2011) High survival rate after two-stage resection of advanced colorectal liver metastases: response-based selection and complete resection define outcome. J Clin Oncol 29:1083-1090. https://doi.org/10.1200/JCO.2010. 32.6132

53. Tsim N, Healey AJ, Frampton AE et al (2011) Two-stage resection for bilobar colorectal liver metastases: R0 resection is the key. Ann Surg Oncol 18:1939-1946. https://doi.org/10.1245/s10434010-1533-y
54. Narita M, Oussoultzoglou E, Jaeck D et al (2011) Two-stage hepatectomy for multiple bilobar colorectal liver metastases. Br J Surg 98:1463-1475. https://doi.org/10.1002/bjs. 7580

55. Muratore A, Zimmitti G, Ribero D et al (2012) Chemotherapy between the first and second stages of a two-stage hepatectomy for colorectal liver metastases: should we routinely recommend it? Ann Surg Oncol 19:1310-1315. https://doi.org/10.1245/s10434011-2069-5

56. Turrini O, Ewald J, Viret F et al (2012) Two-stage hepatectomy: who will not jump over the second hurdle? Eur J Surg Oncol 38: 266-273. https://doi.org/10.1016/j.ejso.2011.12.009

57. Shindoh J, Vauthey J-N, Zimmitti G et al (2013) Analysis of the efficacy of portal vein embolization for patients with extensive liver malignancy and very low future liver remnant volume, including a comparison with the associating liver partition with portal vein ligation for staged hepatectomy approach. J Am Coll Surg 217:126-133; discussion 133-134. https://doi.org/10.1016/j. jamcollsurg.2013.03.004

58. Fuks D, Nomi T, Ogiso S et al (2015) Laparoscopic two-stage hepatectomy for bilobar colorectal liver metastases. Br J Surg 102:1684-1690. https://doi.org/10.1002/bjs.9945

59. Passot G, Chun YS, Kopetz SE et al (2016) Predictors of safety and efficacy of 2-stage hepatectomy for bilateral colorectal liver metastases. J Am Coll Surg 223:99-108. https://doi.org/10.1016/j. jamcollsurg.2015.12.057

60. Chun YS, Vauthey J-N, Ribero D et al (2007) Systemic chemotherapy and two-stage hepatectomy for extensive bilateral colorectal liver metastases: perioperative safety and survival. J Gastrointest Surg 11:1498-1504; discussion 1504-1505. https:// doi.org/10.1007/s1 1605-007-0272-2

61. Levi Sandri GB, Santoro R, Vennarecci G et al (2015) Two-stage hepatectomy, a 10 years experience. Updat Surg 67:401-405. https://doi.org/10.1007/s13304-015-0332-1

62. Okumura S, Goumard C, Gayet B et al (2019) Laparoscopic versus open two-stage hepatectomy for bilobar colorectal liver metastases: a bi-institutional, propensity score-matched study. Surgery 166:959-966. https://doi.org/10.1016/j.surg.2019.06.019

63. Kawaguchi Y, Lillemoe HA, Vauthey J-N (2019) Dealing with an insufficient future liver remnant: portal vein embolization and two-stage hepatectomy. J Surg Oncol 119:594-603. https://doi. org $/ 10.1002 /$ jso. 25430

64. de GraafW, van den Esschert JW, van Lienden KP, van Gulik TM (2009) Induction of tumor growth after preoperative portal vein embolization: is it a real problem? Ann Surg Oncol 16:423-430. https://doi.org/10.1245/s10434-008-0222-6

65. Hoekstra LT, van Lienden KP, Doets A et al (2012) Tumor progression after preoperative portal vein embolization. Ann Surg 256:812-817; discussion 817-818. https://doi.org/10.1097/SLA. 0b013e3182733f09

66. Goéré D, Farges O, Leporrier J et al (2006) Chemotherapy does not impair hypertrophy of the left liver after right portal vein obstruction. J Gastrointest Surg 10:365-370. https://doi.org/10. 1016/j.gassur.2005.09.001

67. Quénet F, Pissas M-H, Gil H et al (2019) Two-stage hepatectomy for colorectal liver metastases: pathologic response to preoperative chemotherapy is associated with second-stage completion and longer survival. Surgery 165:703-711. https://doi.org/10.1016/j. surg.2018.10.006

68. Fischer C, Melstrom LG, Arnaoutakis D et al (2013) Chemotherapy after portal vein embolization to protect against tumor growth during liver hypertrophy before hepatectomy. JAMA Surg 148:1103-1108. https://doi.org/10.1001/jamasurg. 2013.2126

69. Schnitzbauer AA, Lang SA, Goessmann H et al (2012) Right portal vein ligation combined with in situ splitting induces rapid left lateral liver lobe hypertrophy enabling 2-staged extended right 
hepatic resection in small-for-size settings. Ann Surg 255:405414. https://doi.org/10.1097/SLA.0b013e31824856f5

70. Knoefel WT, Gabor I, Rehders A et al (2013) In situ liver transection with portal vein ligation for rapid growth of the future liver remnant in two-stage liver resection. Br J Surg 100:388-394. https://doi.org/10.1002/bjs.8955

71. Croome KP, Hernandez-Alejandro R, Parker M et al (2015) Is the liver kinetic growth rate in ALPPS unprecedented when compared with PVE and living donor liver transplant? A multicentre analysis. HPB 17:477-484. https://doi.org/10.1111/hpb.12386

72. Chia DKA, Yeo Z, Loh SEK et al (2018) Greater hypertrophy can be achieved with associating liver partition with portal vein ligation for staged hepatectomy compared to conventional staged hepatectomy, but with a higher price to pay? Am J Surg 215:131-137. https://doi.org/10.1016/j.amjsurg.2017.08.013

73. Sandström P, Røsok BI, Sparrelid E et al (2018) ALPPS improves resectability compared with conventional two-stage hepatectomy in patients with advanced colorectal liver metastasis: results from a scandinavian multicenter randomized controlled trial (LIGRO Trial). Ann Surg 267:833-840. https://doi.org/10.1097/SLA. 0000000000002511

74. de Santibañes E, Clavien P-A (2012) Playing Play-Doh to prevent postoperative liver failure: the "ALPPS" approach. Ann Surg 255: 415-417. https://doi.org/10.1097/SLA.0b013e318248577d

75. Eshmuminov D, Raptis DA, Linecker M et al (2016) Metaanalysis of associating liver partition with portal vein ligation and portal vein occlusion for two-stage hepatectomy. Br J Surg 103:1768-1782. https://doi.org/10.1002/bjs.10290

76. Linecker M, Kuemmerli C, Clavien P-A, Petrowsky H (2019) Dealing with insufficient liver remnant: associating liver partition and portal vein ligation for staged hepatectomy. J Surg Oncol 119: 604-612. https://doi.org/10.1002/jso.25435

77. Schadde E, Ardiles V, Robles-Campos R et al (2014) Early survival and safety of ALPPS: first report of the International ALPPS Registry. Ann Surg 260:829-836; discussion 836-838. https://doi. org/10.1097/SLA.0000000000000947

78. Truant S, Scatton O, Dokmak S et al (2015) Associating liver partition and portal vein ligation for staged hepatectomy (ALPPS): impact of the inter-stages course on morbi-mortality and implications for management. Eur J Surg Oncol 41:674682. https://doi.org/10.1016/j.ejso.2015.01.004

79. Kremer M, Manzini G, Hristov B et al (2015) Impact of neoadjuvant chemotherapy on hypertrophy of the future liver remnant after associating liver partition and portal vein ligation for staged hepatectomy. J Am Coll Surg 221:717-728.e1. https://doi.org/10. 1016/j.jamcollsurg.2015.05.017

80. Wanis KN, Linecker M, Madenci AL et al (2020) Variation in complications and mortality following ALPPS at early-adopting centers. HPB 23(1):46-55. https://doi.org/10.1016/j.hpb.2020.04. 009

81. Nadalin S, Capobianco I, Li J et al (2014) Indications and limits for associating liver partition and portal vein ligation for staged hepatectomy (ALPPS). Lessons Learned from 15 cases at a single centre. Z Gastroenterol 52:35-42. https://doi.org/10.1055/s-00331356364

82. Schadde E, Raptis DA, Schnitzbauer AA et al (2015) Prediction of mortality after ALPPS stage-1: an analysis of 320 patients from the International ALPPS Registry. Ann Surg 262:780-785; discussion 785-786. https://doi.org/10.1097/SLA. 0000000000001450

83. Tanaka K, Matsuo K, Murakami T et al (2015) Associating liver partition and portal vein ligation for staged hepatectomy (ALPPS): short-term outcome, functional changes in the future liver remnant, and tumor growth activity. Eur J Surg Oncol 41:506-512. https://doi.org/10.1016/j.ejso.2015.01.031
84. Ratti F, Schadde E, Masetti M et al (2015) Strategies to increase the resectability of patients with colorectal liver metastases: a multi-center case-match analysis of ALPPS and conventional two-stage hepatectomy. Ann Surg Oncol 22:1933-1942. https:// doi.org/10.1245/s10434-014-4291-4

85. Linecker M, Stavrou GA, Oldhafer KJ et al (2016) The ALPPS risk score: avoiding futile use of ALPPS. Ann Surg 264:763-771. https://doi.org/10.1097/SLA.0000000000001914

86. Linecker M, Kuemmerli C, Kambakamba P et al (2019) Performance validation of the ALPPS risk model. HPB 21:711721. https://doi.org/10.1016/j.hpb.2018.10.003

87. Linecker M, Björnsson B, Stavrou GA et al (2017) Risk adjustment in ALPPS is associated with a dramatic decrease in early mortality and morbidity. Ann Surg 266:779-786. https://doi.org/ 10.1097/SLA.0000000000002446

88. Linecker M, Kambakamba P, Reiner CS et al (2017) How much liver needs to be transected in ALPPS? A translational study investigating the concept of less invasiveness. Surgery 161:453464. https://doi.org/10.1016/j.surg.2016.08.004

89. Petrowsky H, Györi G, de Oliveira M et al (2015) Is partialALPPS safer than ALPPS? A single-center experience. Ann Surg 261:e90-e92. https://doi.org/10.1097/SLA. 0000000000001087

90. Machado MAC, Makdissi FF, Surjan RC (2012) Totally laparoscopic ALPPS is feasible and may be worthwhile. Ann Surg 256: e13; author reply e16-19. https://doi.org/10.1097/SLA. 0b013e318265ff2e

91. Robles R, Parrilla P, López-Conesa A et al (2014) Tourniquet modification of the associating liver partition and portal ligation for staged hepatectomy procedure. Br J Surg 101:1129-1134; discussion 1134. https://doi.org/10.1002/bjs. 9547

92. de Santibañes E, Alvarez FA, Ardiles V et al (2016) Inverting the ALPPS paradigm by minimizing first stage impact: the MiniALPPS technique. Langenbeck's Arch Surg 401:557-563. https://doi.org/10.1007/s00423-016-1424-1

93. Linecker M, Kambakamba P, Raptis DA et al (2020) ALPPS in neuroendocrine liver metastases not amenable for conventional resection - lessons learned from an interim analysis of the International ALPPS Registry. HPB 22:537-544. https://oi.org/ 10.1016/j.hpb.2019.08.011

94. Li J, Moustafa M, Linecker M et al (2020) ALPPS for locally advanced intrahepatic cholangiocarcinoma: did aggressive surgery lead to the oncological benefit? An International Multicenter Study. Ann Surg Oncol 27:1372-1384. https://doi.org/10. 1245/s10434-019-08192-Z

95. Chan A, Zhang WY, Chok K, et al (2019) ALPPS versus portal vein embolization for hepatitis-related hepatocellular carcinoma: a changing paradigm in modulation of future liver remnant before major hepatectomy. Ann Surg. https://doi.org/10.1097/SLA. 0000000000003433

96. Chan ACY, Lo CM (2020) Associating liver partition and portal vein ligation for staged hepatectomy (ALPPS)-pushing the envelope in modulation of future liver remnant before major hepatectomy. Hepatobiliary Surg Nutr 9:80-82. https://doi.org/10.21037/ hbsn.2019.10.28

97. Balci D, Kirimker EO, Üstüner E et al (2020) Stage I-laparoscopy partial ALPPS procedure for perihilar cholangiocarcinoma. J Surg Oncol 121:1022-1026. https://doi.org/10.1002/jso.25868

98. Raptis DA, Linecker M, Kambakamba P et al (2019) Defining benchmark outcomes for ALPPS. Ann Surg 270:835-841. https://doi.org/10.1097/SLA.0000000000003539

99. Hasselgren K, Røsok BI, Larsen PN et al (2019) ALPPS improves survival compared with TSH in patients affected of CRLM: survival analysis from the randomized controlled trial LIGRO. Ann Surg 273(3):442-448. https://doi.org/10.1097/SLA. 0000000000003701 
100. Liu Y, Yang Y, Gu S, Tang K (2019) A systematic review and meta-analysis of associating liver partition and portal vein ligation for staged hepatectomy (ALPPS) versus traditional staged hepatectomy. Medicine (Baltimore) 98:e15229. https://doi.org/10. 1097/MD.0000000000015229

101. Line P-D, Hagness M, Berstad AE et al (2015) A Novel concept for partial liver transplantation in nonresectable colorectal liver metastases: the RAPID concept. Ann Surg 262:e5-e9. https:// doi.org/10.1097/SLA.0000000000001165

102. Renz JF, Yersiz H, Reichert PR et al (2003) Split-liver transplantation: a review. Am J Transplant Off J Am Soc Transplant Am Soc Transplant Surg 3:1323-1335. https://doi.org/10.1046/j. 1600-6135.2003.00254.x

103. Nadalin S, Settmacher U, Rauchfuß F et al (2020) RAPID procedure for colorectal cancer liver metastasis. Int J Surg 82S:93-96. https://doi.org/10.1016/j.ijsu.2020.03.078

104. Königsrainer A, Templin S, Capobianco I et al (2019) Paradigm shift in the management of irresectable colorectal liver metastases: living donor auxiliary partial orthotopic liver transplantation in combination with two-stage hepatectomy (LD-RAPID). Ann Surg 270:327-332. https://doi.org/10.1097/SLA. 0000000000002861

105. Rauchfuß F, Nadalin S, Königsrainer A, Settmacher U (2019) Living donor liver transplantation with two-stage hepatectomy for patients with isolated, irresectable colorectal liver-the LIVER-T(W)O-HEAL study. World J Surg Oncol 17:11. https:// doi.org/10.1186/s12957-018-1549-5

106. Balci D, Kirimker EO, Bingol Kologlu M, et al (2020) A new approach for increasing availability of liver grafts and donor safety in living donor liver transplantation: LD-RAPID procedure in the cirrhotic setting with hepatocellular carcinoma. Liver Transpl. https://doi.org/10.1002/lt.25855

107. Ravaioli M, Fallani G, Cescon M et al (2018) Heterotopic auxiliary segment 2-3 liver transplantation with delayed total hepatectomy: new strategies for nonresectable colorectal liver metastases. Surgery 164:601-603. https://doi.org/10.1016/j.surg.2018.05.021

108. Ravaioli M, Brandi G, Siniscalchi A et al (2020) Heterotopic segmental liver transplantation on splenic vessels after splenectomy with delayed native hepatectomy after graft regeneration: a new technique to enhance liver transplantation. Am J Transplant 21(2):870-875. https://doi.org/10.1111/ajt.16222

109. Rammohan A, Reddy MS, Line P-D, Rela M (2020) Heterotopic liver transplantation: temporary solution, permanent problem? Am J Transplant 21(2):903-904. https://doi.org/10.1111/ajt.16271

Publisher's note Springer Nature remains neutral with regard to jurisdictional claims in published maps and institutional affiliations. 